\title{
Peroral cholangiopancreatoscopy as a rescue method for a trapped pancreatic guidewire
}

Peroral cholangiopancreatoscopy is an endoscopic technique that enables direct visual examination and video-guided tissue sampling. The technique has improved the ability to identify pancreaticobiliary diseases and has been useful for treating complex bile and pancreatic duct stones [1 - 3]. It is increasingly being used as a therapeutic procedure [4].

We present the case of a 55-year-old man with a history of chronic calcifying pancreatitis of alcoholic etiology. He was admitted for resolution of symptomatic pancreatic lithiasis using endoscopic retrograde cholangiopancreatography. To our knowledge, there are no reports of rescue maneuvers using cholangiopancreatoscopes.

During the procedure, the ascending duodenal part was hardly reached owing to a tortuous duct due to the chronic pancreatitis. The guidewire was placed in the pancreatic duct at the first attempt. Initially without the use of contrast, pancreatic calcifications were observed in the fluoroscopic image. After opacification, a very dilated Wirsung duct $(10 \mathrm{~mm})$ was observed, and stones were confirmed in the pancreas body and tail ( $\triangleright$ Fig. 1 a). Sphincterotomy and cleaning of the main pancreatic duct were performed. During the cleaning maneuvers, we could not withdraw the guidewire from the pancreatic tail as it had become trapped between the stones. Despite the use of standard force, the pancreatic guidewire

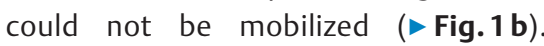
Sphincteroplasty with a balloon was performed, followed by pancreatoscopy with the SpyGlass system (Boston Scientific, Marlborough, Massachusetts, USA). Under direct view it was possible to see the guidewire impacted between pancreatic stones. We started to wash through the SpyGlass working channel to move the stones and were eventually able to release the guidewire ( $\triangleright$ Video 1$)$. Litho-

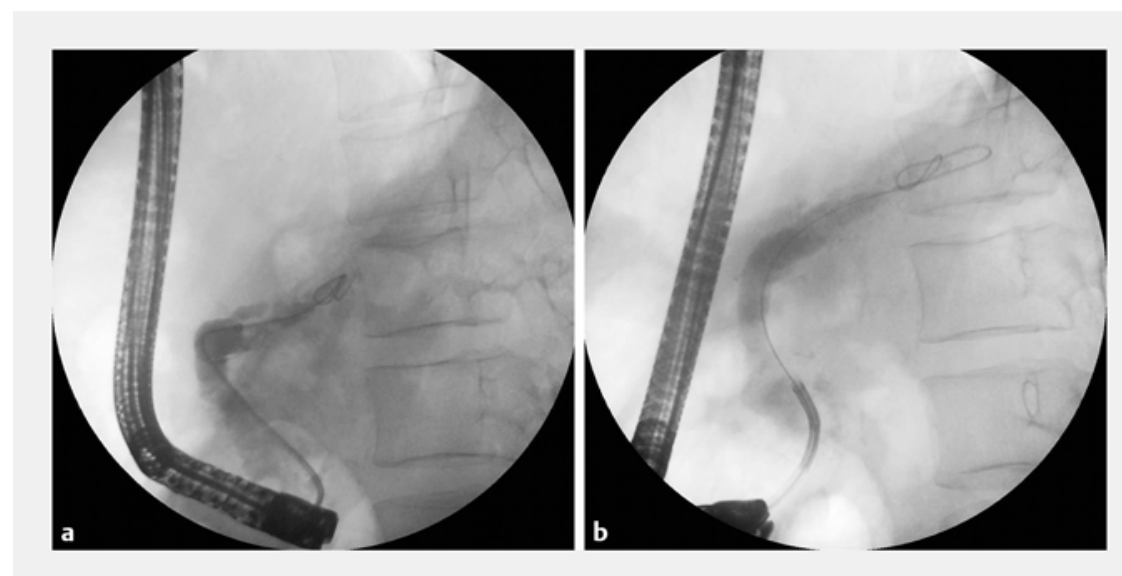

Fig. 1 Fluoroscopy. a Dilated tortuous pancreatic duct. b Trapped guidewire in the pancreatic tail.

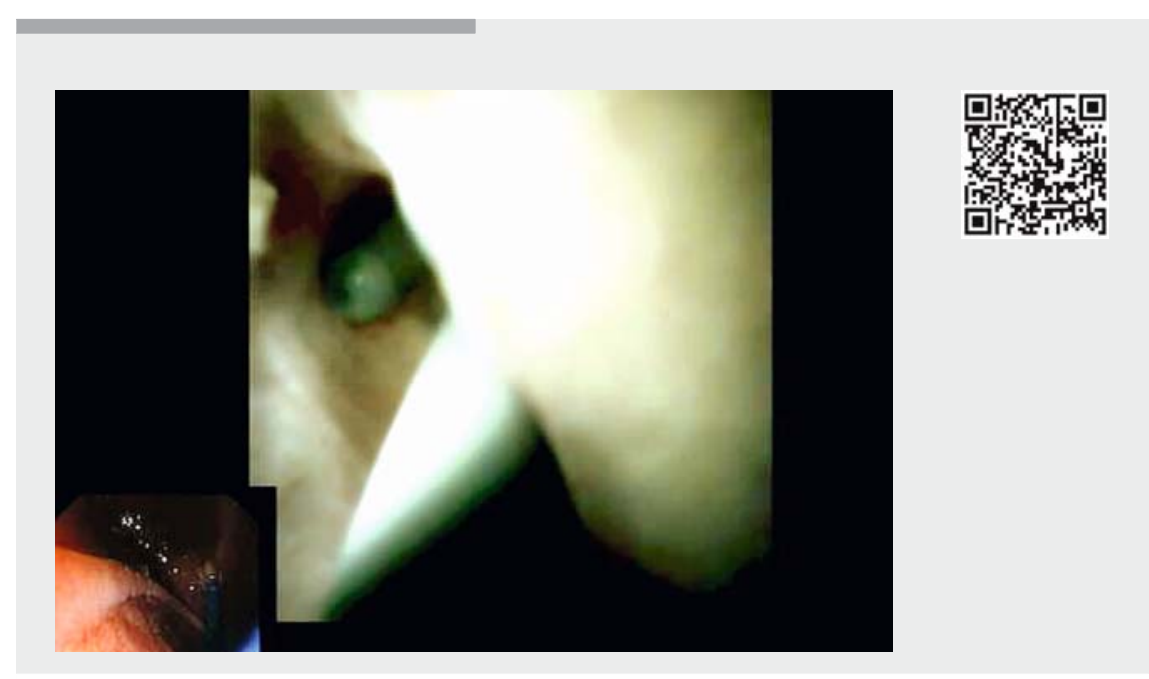

Video 1 Peroral cholangiopancreatoscopy showing endoscopic maneuvers to rescue a trapped pancreatic guidewire.

tripsy was then performed using a laser, and most, but not all, of the stone fragments were extracted. Finally, a plastic prosthesis $(9 \mathrm{~cm} \times 10 \mathrm{Fr})$ was inserted.

Endoscopy_UCTN_Code_CPL_1AK_2AC

\section{Competing interests}

Dr. Pons Beltrán has received fees for serving as a consultant for Boston Scientific. 
The authors

Rodrigo Mansilla-Vivar ${ }^{1,2,3}$, Noelia AlonsoLázaro $^{1,2}$, Lidia Argüello-Viudez ${ }^{1,2}$, Marta Ponce Romero ${ }^{1,2}$, Marco BustamanteBalen $^{1,2}$, Vicente Pons Beltrán ${ }^{1,2}$

1 Digestive Endoscopy Unit, Digestive Diseases Department, La Fe Polytechnic University Hospital, Valencia, Spain

2 Gastrointestinal Endoscopy Research Group, IIS Hospital La Fe, Valencia, Spain

3 Digestive Endoscopy Unit, Hospital Puerto Montt, Puerto Montt, Chile

Corresponding author

Rodrigo Mansilla-Vivar, MD, MHA

Gastrointestinal Endoscopy Research Group, IIS Hospital La Fe, Avda. Fernando Abril Martorell, n: 106, 46126 Valencia, Spain Fax: +34-64-5157931

rmansillavivar@gmail.com

\section{References}

[1] Bhandari S, Bathini R, Sharma A et al. Usefulness of single-operator cholangioscopyguided laser lithotripsy in patients with Mirizzi syndrome and cystic duct stones: experience at a tertiary care center. Gastrointest Endosc 2016; 84: 56-61

[2] Chen YK, Parsi MA, Binmoeller KF et al. Peroral cholangioscopy (POC) using a disposable steerable single operator catheter for biliary stone therapy and assessment of indeterminate strictures - a multicenter experience using Spyglass. Gastrointest Endosc 2009; 69: AB264 - AB265

[3] Nakajima M, Akasaka Y, Yamaguchi K et al. Direct endoscopic visualization of the bile and pancreatic duct systems by peroral cholangiopancreatoscopy (PCPS). Gastrointest Endosc 1978; 24: 141 - 145

[4] Pereira P, Peixoto A, Andrade P et al. Peroral cholangiopancreatoscopy with the SpyGlass ${ }^{\circledR}$ system: what do we know 10 years later. J Gastrointestin Liver Dis 2017; 26: $165-170$

\section{Bibliography}

DOI https://doi.org/10.1055/a-0820-1160

Published online: 11.1.2019

Endoscopy 2019; 51: E59-E60

(c) Georg Thieme Verlag KG

Stuttgart · New York

ISSN 0013-726X

\section{ENDOSCOPY E-VIDEOS}

https://eref.thieme.de/e-videos

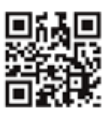

Endoscopy E-Videos is a free access online section, reporting on interesting cases and new

techniques in gastroenterological endoscopy. All papers include a high quality video and all contributions are freely accessible online.

This section has its own submission website at https://mc.manuscriptcentral.com/e-videos 